\title{
Immunohistochemical analysis of collagen expression in uterine leiomyomata during the menstrual cycle
}

\author{
MASAAKI IWAHASHI ${ }^{1}$, YASUTERU MURAGAKI ${ }^{2}$, MAKOTO IKOMA $^{1}$, YASUSHI MABUCHI ${ }^{1}$, \\ AYA KOBAYASHI $^{1}$, YUUKO TANIZAKI ${ }^{1}$ and KAZUHIKO INO ${ }^{1}$
}

Departments of ${ }^{1}$ Obstetrics and Gynecology, and ${ }^{2}$ Pathology, Wakayama Medical University, Wakayama 641-0012, Japan

Received October 27, 2010; Accepted December 27, 2010

DOI: $10.3892 / \mathrm{etm} .2011 .186$

\begin{abstract}
To investigate the possible involvement of collagen in the characteristic features of human leiomyoma, type I, III and IV collagen expression was determined at the protein level in normal myometrium and leiomyoma tissues throughout the menstrual cycle. The tissues were obtained from 40 pre-menopausal women (29-53 years of age) at various stages of the menstrual cycle who were undergoing abdominal hysterectomy for symptomatic uterine leiomyoma. Immunohistochemical staining was performed with specific monoclonal antibodies against type I, III and IV collagen in the leiomyoma and the myometrial tissues. Immunohistochemical analysis revealed that type I collagen expression was increased in the leiomyoma tissues at the protein level as compared to that in the normal myometrium tissues throughout the menstrual cycle. These results suggest that increased expression of type I collagen plays a key role in the pathogenesis of uterine leiomyoma.
\end{abstract}

\section{Introduction}

The extracellular matrix (ECM) is considered to play an crucial role in the stability of tissues and in regulating the growth and differentiation of cells $(1,2)$. Synthesis, accumulation and catabolism of the ECM occur during wound healing and during the initiation and progression of numerous diseases (3).

Moreover, it is generally acknowledged that the ECM does not function as a passive scaffold for connective tissue within the organ architecture, but also plays an 'informational' role through a network of interactions between cells and signal molecules. This role is crucial in the control of cellular proliferation and motility during histogenesis for maintenance of tissue homeostasis and in cancer development.

Correspondence to: Dr Masaaki Iwahashi, Department of Obstetrics and Gynecology, Wakayama Medical University, 811-1 Kimiidera, Wakayama 641-0012, Japan

E-mail: masaaki@wakayama-med.ac.jp

Key words: collagen, human uterine myoma, immunohistochemistry
Uterine leiomyomata, or fibroids, are the most common pelvic tumors in women of reproductive age. Despite their prevalence and impact on normal reproductive and menstrual function, little is understood regarding their basic biology and growth. Uterine leiomyoma contains abundant quantities of ECM (4-7). However, the proteins comprising the ECM and the regulation of their expression have yet to be characterized. The study of ECM of uterine leiomyomata and normal myometrium is key in the elucidation of the growth of these neoplasms. Leiomyomata exhibit a low mitotic index, yet undergo rapid growth and, conversely, a rapid decrease in size upon GnRH agonist treatment (8). A significant component of this growth and/or regression may be mediated by changes in the composition and content of the ECM. Therefore, the precise control of ECM metabolism in leiomyomata and normal myometrium is critical for the pathology and development of uterine leiomyomata.

In the present study, the expression of various types of collagen, a major component of ECM, was investigated in human uterine leiomyoma and normal myometrium tissues by immunofluorescent staining. The results were compared to normal myometrium obtained throughout the menstrual cycle.

\section{Materials and methods}

This study was approved by the Committee on Investigations Involving Human Subjects of Wakayama Medical College. Informed consent was obtained from each subject after the purpose and nature of the study had been fully explained.

Tissues. Leiomyomata and matched myometrium were processed for immunohistochemistry and SDS-PAGE. The tissues were obtained from 40 pre-menopausal women (29-53 years of age) who were undergoing abdominal hysterectomy for symptomatic uterine leiomyomata at various stages of the menstrual cycle. None of the patients received any hormone therapy prior to surgery. The stage of the menstrual cycle was determined by histological dating of the endometrium for all secretory phase samples. Proliferative phase samples were dated by either dating the endometrium or determining the date of the last menstrual period. The leiomyoma and corresponding myometrium specimens from the proliferative $(n=20)$ and secretory $(n=20)$ phase were studied. No submucosal leiomyomata were collected so as 
to avoid possible contamination with endometrium. The leiomyomata and myometrium tissues were immediately frozen in liquid nitrogen.

Primary antibodies. Monoclonal antibodies (mAbs) against each $\alpha 1$ chain of human type I, III and IV collagen were used. Preparation of the antibodies has been previously described (9). In brief, BALB/C mice were immunized with each type of collagen, after it had been extracted from human placentas. The spleen cells of the mice were then hybridized with myeloma cells. Following hypoxanthine-aminopterinethymidine (HAT) selection, positive hybrids were identified using an enzyme-linked immunosorbent assay. The specificity of each antibody was determined using immunoblotting or inhibition in an enzyme-linked immunosorbent assay. No cross-reaction was observed among the antibodies.

Immunohistochemistry. Immunohistochemical analysis was performed using the standard indirect immunofluorescence method. In brief, $3-\mu \mathrm{m}$ frozen sections were rehydrated in phosphate-buffered saline (PBS) at room temperature and then incubated with the primary antibody (diluted 1:100 in PBS) for $12 \mathrm{~h}$ at $4^{\circ} \mathrm{C}$ in a humidified chamber. Following incubation, the sections were washed twice in PBS for $3 \mathrm{~min}$. Each section was then incubated for $1 \mathrm{~h}$ at room temperature with human plasma-preabsorbed, fluorescein isothiocyanateconjugated goat antibodies against mouse immunoglobulins diluted 1:100 in PBS (Organon Teknik, Co., West Chester, PA, USA). Subsequently, the sections were washed again in PBS, mounted in buffered glycerol and examined under a fluorescence microscope (Olympus Co., Tokyo, Japan).

\section{Results}

The control sections were stained with goat antibodies against mouse immunoglobulin $\mathrm{G}$ without prior application of the appropriate primary antibody (Figs. 1A, 2A and 3A). When the mAbs were first allowed to react with an excess of each specific type of collagen, no immunostaining was observed.

The intensity and distribution of immunohistochemistry for type I, III and IV collagen in the myometrium and leiomyoma samples showed no significant difference between the proliferative and secretory phases, respectively.

Immunostaining with the mAbs against type I and III collagen showed a fibrillary pattern in the ECM of the myometrium and the leiomyomata (Figs. $1 \mathrm{~B}$ and $\mathrm{C}$ and $2 \mathrm{~B}$ and $\mathrm{C}$ ). Immunostaining for type I collagen showed an intense and accumulated pattern in much larger areas of the ECM in the leiomyomata as compared to the normal myometrium (Fig. 1B and C). However, immunostaining for type III collagen showed a similarly intense and microfibrillary pattern in the ECM of the leiomyomata and the normal myometrium (Fig. 2B and C).

Immunostaining with the mAbs against type IV collagen showed positive staining of a similar intensity in the myometrium and the leiomyomata (Fig. 3) throughout the menstrual cycle. In the leiomyomata, type IV collagen was localized in the ECM-embedded bundles of smooth muscle cells, whereas areas of ECM accumulation were negative for this collagen (Fig. 3C). Similarly, in the myometrial samples, type IV collagen surrounded smooth muscle cell bundles, but did not contribute
Table I. Immunostaining of human uterine myometrium and myoma with antibodies for type I, III and IV collagens.

\begin{tabular}{lcccc}
\hline & \multirow{2}{*}{$\begin{array}{c}\text { No. of } \\
\text { patients }\end{array}$} & \multicolumn{3}{c}{ Collagen type } \\
\cline { 3 - 5 } & & I & III & IV \\
\hline Myometrium & 20 & ++ & ++ & + \\
Myoma uteri & 20 & +++ & ++ & + \\
\hline
\end{tabular}

Intensities of immunostaining were graded subjectively: + , weak staining; ++ , intense staining; +++ , very intense staining.

to the formation of larger septa separating the muscle fibers. The intensity of staining of the myometrium and leiomyomata by each of the antibodies against various types of collagen was subjectively graded from $1+$ to $3+$, and the results are summarized in Table I. Although the immunostaining did not allow an accurate quantitative comparison of ECM proteins between the leiomyomata and myometrium, our results suggest that the leiomyomata contained more type I collagen than the normal myometrium due to the larger areas of ECM. There appeared to be no variation in the staining of these collagen types in tissues obtained at different times throughout the menstrual cycle.

\section{Discussion}

In the present study, we investigated changes in the composition of the ECM, including type I, III and IV collagens, in human leiomyomata and normal myometrium tissues obtained throughout the menstrual cycle.

Although type I and III collagens are commonly found in combination, our present study showed that the ratios of type I collagen in the tissues of leiomyomata were significantly higher than those in the normal myometrium throughout the menstrual cycle. However, immunostaining for type III and IV collagen demonstrated a similar pattern in the leiomyomata and the normal myometrium throughout the menstrual cycle. Thus, type I collagen deposition may result in the fibrotic nature of leiomyomata, so called 'fibroids'. Type I collagen has been demonstrated in the human skin (10) and in human atherosclerosis $(11,12)$. One possible cause is an increase in the density of cells in the leiomyoma tissues.

Cell density-dependent effects have been previously reported in various types of cell, including mesangial $(13,14)$, endothelial $(15,16)$, vascular smooth muscle $(17,18)$, fibroblasts $(19,20)$ and primitive mesenchymal cells (21). It has been suggested that cell density may modulate biological behavior, with changes in signal-transduction responses to hormonal stimulation in growth, in the synthesis and composition of the ECM, and in the synthesis of specific proteins $(13,14)$. Therefore, our findings suggest that leiomyomata exhibit an alteration in cell density or proliferation of their cells and that accumulation of ECM, particularly increased type I collagen in leiomyoma tissues, may play a key role in biological behavior in terms of the reaction to ovarian hormones, such as estrogen and progesterone, as well as cytokines and growth factors, such as TGF- $\beta$ (22-24). 


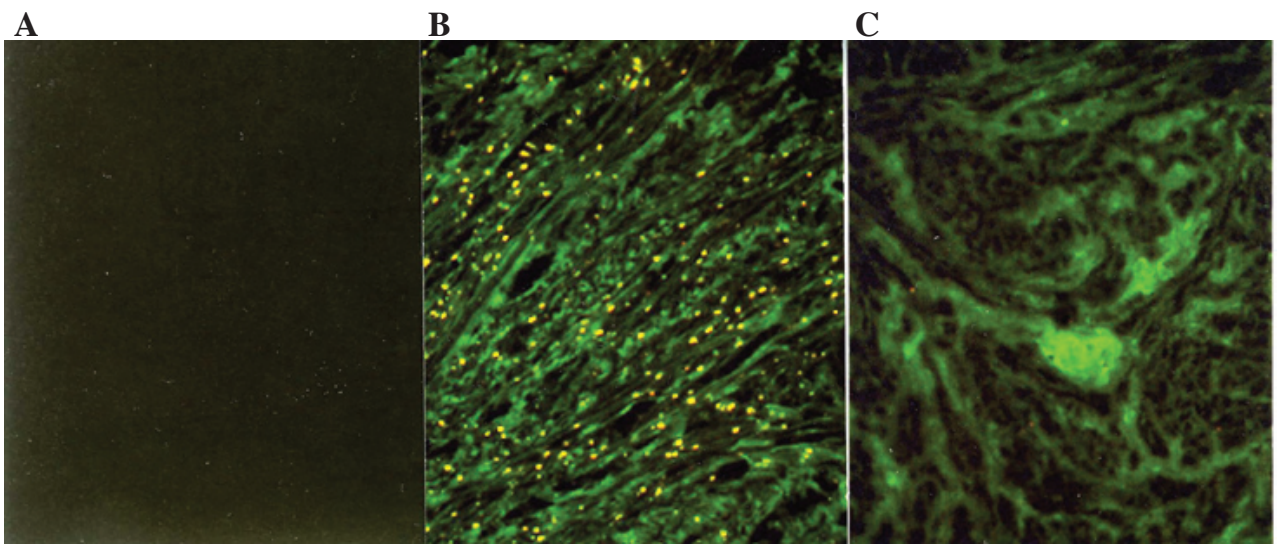

Figure 1. Immunofluorescence micrographs of normal myometrium and leiomyomata with immunostaining by an mAb specific for type I collagen. (A) No immunofluorescence was observed in the control section. Strong immunofluorescence specific for type I collagen is diffusely distributed in the ECM of (C) the leiomyomata as compared to (B) the normal myometrium. The immunostaining of tissues from 19 additional patients yielded similar results (original magnification, x125).

A

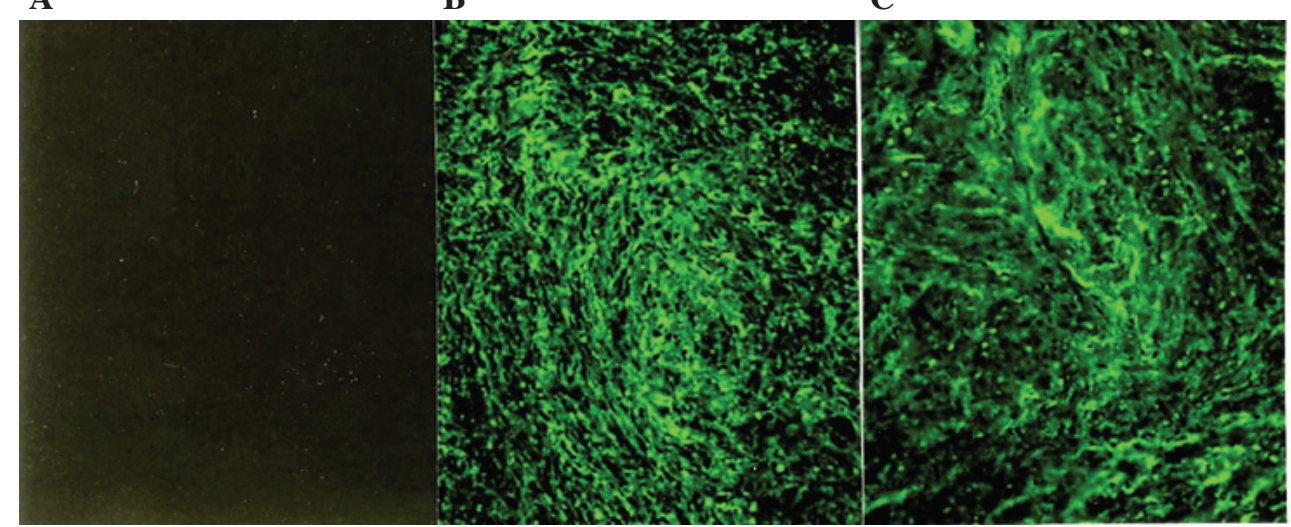

Figure 2. Immunofluorescence micrographs of normal myometrium and leiomyomata with immunostaining by a monoclonal antibody specific for type III collagen. (A) No immunofluorescence is recognized in the control section. Strong immunofluorescence specific for type III collagen is diffusely distributed in the ECM of (B) the myometrium and (C) the leiomyomata. The immunostaining of tissues from 19 additional patients yielded similar results (original magnification, x125).

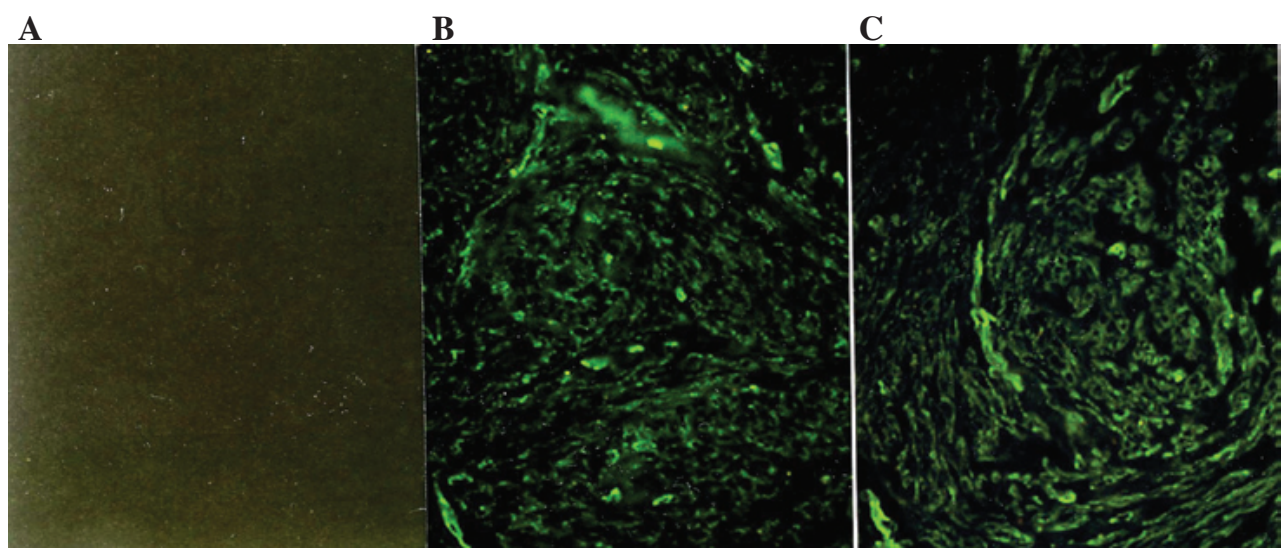

Figure 3. Immunofluorescence micrographs of human myometrium and leiomyoma samples with immunostaining by a monoclonal antibody specific for type IV collagen. (A) No immunofluorescence is recognized in the control section. (B) In normal myometrium, bundles of smooth muscle cells are surrounded by type IV collagen, which is not present in larger septa separating muscle fibers. (C) In the leiomyomata, type IV collagen was localized in bundles of smooth muscle cells, whereas it is absent in areas of ECM accumulation. The immunostaining of tissues from 19 additional patients yielded similar results (original magnification, x125).

Moreover, type I collagen has been shown to mediate cell behavior, including attachment, spread, proliferation and morphogenesis (25-28). Therefore, it is suggested that increased relative levels of type I collagen in leiomyomata provide a biochemical basis for the functional regulation of leiomyoma cells as compared to normal myometrium. 
In conclusion, an increased level of the protein expression of type I collagen was found in the uterine leiomyomata as compared to that in the normal myometrium throughout the menstrual cycle. Therefore, changes in the composition of collagens, which modulate the expression of various cytokines and growth factors, result in the morphologic and functional characteristics of uterine leiomyomata. This study enhanced the understanding of the pathophysiology of uterine leiomyomata in terms of ECM metabolism. Further research is required to elucidate the mechanisms which regulate the expression of genes of other types of collagen in uterine leiomyomata throughout the menstrual cycle and during hormone therapy.

\section{References}

1. Lin CQ and Bissell MJ: Multi-faceted regulation of cell differentiation by extracellular matrix. FASEB J 7: 737-743, 1993.

2. Madri JA and Basson MD: Extracellular matrix-cell interactions: dynamic modulators of cell, tissue and organism structure and function. Lab Invest 66: 519-521, 1992.

3. Haralson MA: Extracellular matrix and growth factors: an integrated interplay controlling tissue repair and progression to disease. Lab Invest 69: 369-372, 1993.

4. Ferency A, Richart RM and Okazaki T: A comparative ultrastructural study of leiomyosarcoma, cellular leiomyoma, and leiomyoma of the uterus. Cancer 28: 1004-1018, 1971.

5. Srewart AE, Friedman AJ, Peck K and Nowak RA: Relative overexpression of collagen type I and collagen III messenger ribonucleic acids by uterine leiomyoma during the proliferative phase of the menstrual cycle. J Clin Endocrinol Metab 79: 900-906, 1994.

6. Catherino WH, Leppert PC, Stenmark MH, et al: Reduced dermatopontin expression is a molecular link between uterine leiomyomas and keloids. Genes Chromosomes Cancer 40: 204-217, 2004

7. Leppert PC, Baginski T, Prupas C, Catherino WH, Pletcher S and Segars JH: Comparative ultrastructure of collagen fibrils in uterine leiomyomas and normal myometrium. Fertil Steril 82 (Suppl 3): 1182-1187, 2004.

8. Chavez NF and Stewart EA: Medical treatment of uterine fibroids. Clin Obstet Gynecol 44: 372-384, 2001.

9. Ooshima A and Muragaki Y: Collagen metabolism in atherogenesis. Ann NY Acad Sci 598: 582-584, 1990.

10. Laemmli UK: Cleavage of structural proteins during the assembly of the head of bacteriophage T4. Nature 227: 680-685, 1970.

11. McCullagh KA and Balian G: Collagen characterisation and cell transformation in human atherosclerosis. Nature 258: 73-75, 1975.

12. Ooshima A: Collagen $\alpha$ B chain: increased proportion in human atherosclerosis. Science 213: 666-668, 1981.

13. Ishimura E, Sterzel RB, Budde K and Kashgarian M: Formation of extracellular matrix by cultured rat mesangial cells. Am J Pathol 134: 843-855, 1989.
14. Worthuis A, Boes A and Grond J: Cell density modulates growth, extracellular matrix, and protein synthesis of cultured rat mesangial cells. Am J Pathol 143: 1209-1219, 1993.

15. Patton WF, Yoon MU, Alexander JS, et al: Expression of simple epithelial cytokeratins in bovine pulmonary microvascular endothelial cells. J Cell Physiol 143: 140-149, 1990.

16. Orpana A, Ranta V, Mikkola T, Viinikka L and Ylikorkala O: Inducible nitric oxide and prostacyclin productions are differently controlled by extracellular matrix and cell density in human vascular endothelial cells. J Cell Biochem 64: 538-546, 1997.

17. Goodman LV and Majack RA: Vascular smooth muscle cells express distinct transforming growth factor- $\beta$ receptor phenotypes as a function of cell density in culture. J Biol Chem 264: 5241-5244, 1989

18. Kato S, Shanley JR and Fox JC: Serum stimulation, cell-cell interactions, and extracellular matrix independently influence smooth muscle cell phenotype in vitro. Am J Pathol 149: 687-697, 1996.

19. Ellis IR and Schor SL: Differential effects of TGF-beta 1 on hyaluronan synthesis by fetal and adult skin fibroblasts: implications for cell migration and wound healing. Exp Cell Res 228: 326-333, 1996.

20. Brenn T, Aoyama T, Francke U and Furthmayr H: Dermal fibroblast culture as a model system for studies of fibrillin assembly and pathogenetic mechanisms: defects in distinct groups of individuals with Marfan's syndrome. Lab Invest 75: 389-402, 1996.

21. Tsonis PA and Goetinck PK: Cell density effects of a tumor promotor on proliferation and chondrogenesis of limb bud mesenchymal cells. Exp Cell Res 190: 247-253, 1990.

22. Tang XM, Dou Q, Zhao Y, McLean F, Davis J and Chegini N: The expression of transforming growth factor-beta and TGF-beta receptor mRNA and protein and the effect of TGF-beta on human myometrial smooth muscle cells in vitro. Mol Hum Reprod 3: 233-240, 1997.

23. Lee BS and Nowak RA: Human leiomyoma smooth muscle cells show increased expression of transforming growth factor-beta 3 (TGF beta 3 ) and altered responses to the antiproliferative effects of TGF beta. J Clin Endocrinol Metab 86: 913-920, 2001.

24. Sozen I and Arici A: Interactions of cytokines, growth factors, and extracellular matrix in the cellular biology of uterine leiomyoma. Fertil Steril 78: 1-12, 2002.

25. Stein CA, Wu S, Voskresenskiy AM, et al: G3139, an anti-BCL-2 antisense oligomer that binds heparin-binding growth factors and collagen I, alters in vitro endothelial cell growth and tubular morphogenesis. Clin Cancer Res 15: 2797-2807, 2009.

26. Hubchak SC, Sparks EE, Hayashida T and Schnaper W: Rac1 promotes TGF- $\beta$-stimulated mesangial cell type I collagen expression through a PI3K/Akt-dependent mechanism. Am J Physiol Renal Physiol 297: F1316-F1323, 2009.

27. Barkan D, El Touny LH, Michalowski AM, et al: Metastatic growth from dormant cells induced by a Col-I-enriched fibrotic environment. Cancer Res 70: 5706-5716, 2010.

28. Moore AB, Yu L, Swartz CD, et al: Human uterine leiomyomaderived fibroblasts stimulate uterine leiomyoma cell proliferation and collagen type I production, and activate RTKs and TGF beta receptor signaling in coculture. Cell Commun Signal 8: 10, 2010. 